\title{
Real-time monitoring of the full-scale flate-plate floor subjected to fire by acoustic emission and energy rate analysis
}

\author{
Chongji Zhu ${ }^{1, \text { a }}$, Yuli Dong ${ }^{2, \mathrm{~b}}$ and Qun Xie ${ }^{1, \mathrm{c}}$ \\ ${ }^{1}$ School of Civil Engineering and Architecture, University of Jinan, Jinan, Shandong Province, \\ China \\ ${ }^{2}$ School of Civil Engineering, Huaqiao University, Xiamen, Fujian Province, China \\ azhuchongji@163.com, bongyl1965@163.com, cea_xieq@ujn.edu.cn
}

Keywords: Acoustic emission; $b$-value; Concrete spalling; The flat-plate floor

Abstract. This paper presents test results of mechanical behavior, failure pattern and energy rate of full-scale flat-plate floor subjected to fire. The experimental results show that crack patterns on top surface of the flat-plate floor under fire consistent with those at ambient temperature. The experimental results also show that concrete spalling has a significant impact on fire resistance of the flat-plate floor. Serious spalling would directly cause failure of concrete structures or members under fire even though they haven't reached their fire resistance. On the basis of experimental results, acoustic emission parameters were analysed, which proved that energy rate has a close relationship with the damage variation rate of the slab and can be used to estimate the damage process of the flat-plate floor under fire.

\section{Introduction}

At present, the technique of acoustic emission has two areas of broad applications. The first is nondestructive evaluation [1-2]. The second is a tool in studies or research [3-4], which are not fundamentally directed toward acoustic emission. As a tool in studies or research the AE technique is frequently applied to monitor the response of concrete and concrete structures under mechanical and chemical loading [5-6]. Thummen et al. studied cyclic fatigue and the lifetime of concrete refraction and found a relationship between AE signals and nonlinear deformation [7]. They pointed out that acoustic emission can be a means of predicting the remaining life of the specimen. Yuyama et al. studied the fatigue property of reinforced concrete slab by acoustic emission and found that the cracking process under fatigue loading can be predicted and evaluated by monitoring AE signals [8]. Most of the studies were focused on the ambient temperature, and few researches had been conducted to study the concrete structures or members under fire by AE technique. In this paper, properties of full-scale flat-plate floor subjected to fire were studied by acoustic emission and analysed by energy rate.

\section{Test Details}

The flat-plate floor specimen was tested at Shandong Jianzhu University in Jinan, China. The slab measured $7.2 \mathrm{~m}$ wide by $7.2 \mathrm{~m}$ long and the thickness was $150 \mathrm{~mm}$. The column distance was $4.2 \times 4.2$ $\mathrm{m}$ and the column size was $0.4 \mathrm{~m} \times 0.4 \mathrm{~m} \times 3 \mathrm{~m}$. The arrangement of reinforcement of the flat-plate floor is shown in Fig. 1 to Fig 3. The flat-plate floor was loaded with a constant uniformly distributed load and heated on the underside with the ISO 834 standard fire curve [9]. 


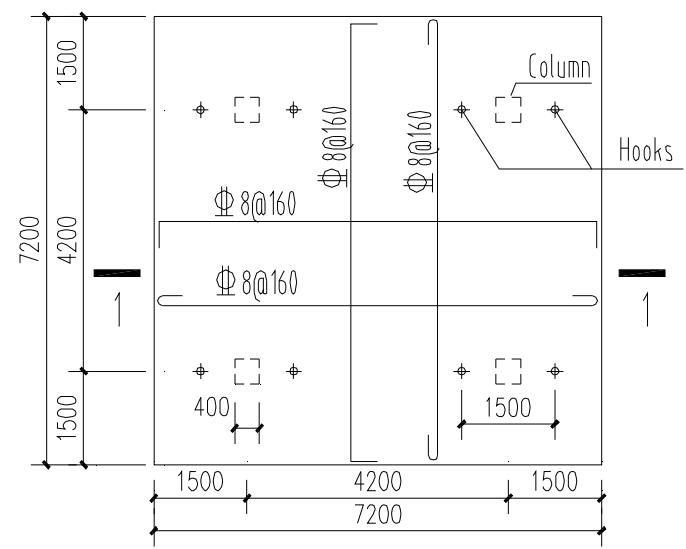

Fig. 1 Arrangement of reinforcement in slab (dimension in $\mathrm{mm}$ )

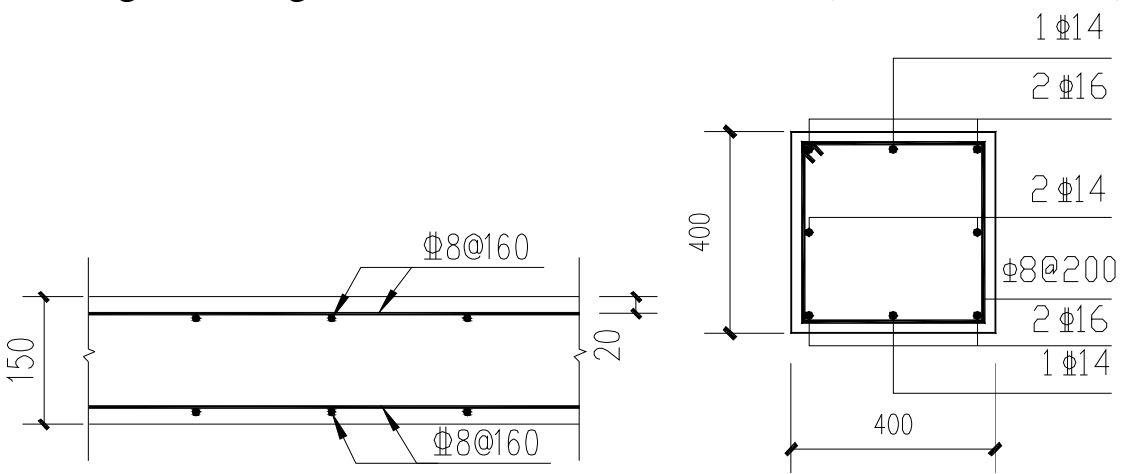

Fig. 2 Details for section 1-1 Fig. 3 Reinforcement arrangement of columns Grade 3 hot-rolled reinforcing bars of $8 \mathrm{~mm}$ diameter were arranged at $160 \mathrm{~mm}$ spacing along both of the two directions. The clear cover was $20 \mathrm{~mm}$ for reinforcement. The yield strength and ultimate strength were 515 and $591 \mathrm{MPa}$, respectively. The yield strength and ultimate strength of bars in column of $14 \mathrm{~mm}$ diameter were 413 and $505 \mathrm{MPa}$ respectively. And the yield strength and ultimate strength of bars in column of $16 \mathrm{~mm}$ diameter were 384 and $511 \mathrm{MPa}$ respectively. Commercial normal weight concrete was used for the flat-plate floor and the specified compressive strength was $30 \mathrm{MPa}$. The cubic compressive strength was $32.6 \mathrm{MPa}$. The concrete moisture content, when tested, was $4.33 \%$.

The arrangement of the specimen in fire-test furnace was shown in Fig.4 and Fig.5. The heated slab served as the upper cover of the furnaces. It is worth noting that there was a $200 \mathrm{~mm}$-thick flexible space, which sealed with alumino-silicate refractory fiber, between the furnace wall and the bottom of the heated slab so that the edges of the slab were free to deflect during the test. Further details for the test setup of the flate-plate floor fire tests were given in Ref. [8].

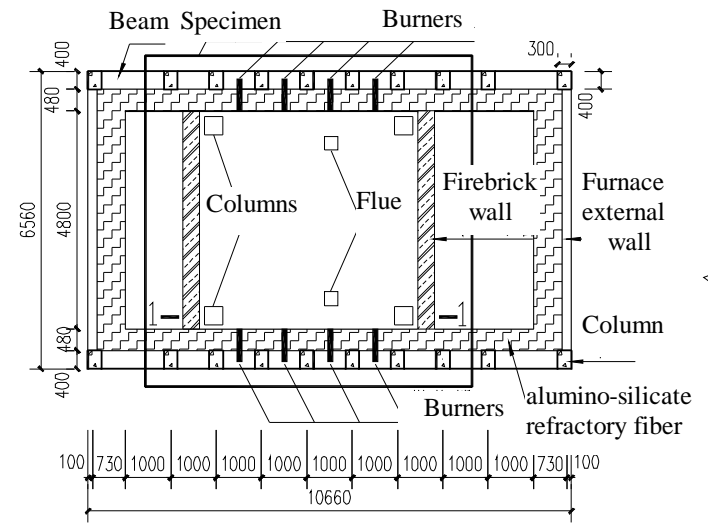

Fig.4 Arrangements of the specimen

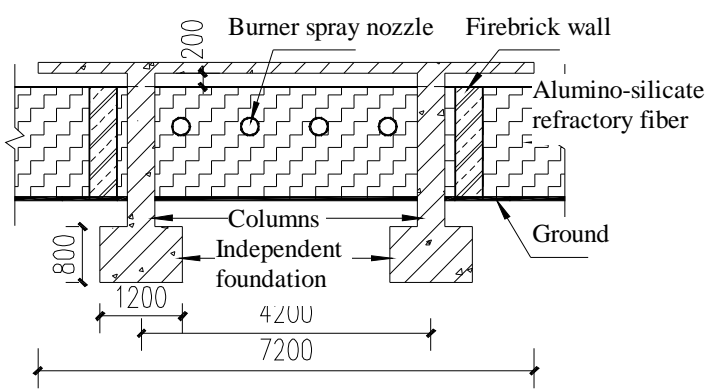

Fig.5 Details for section 1-1 
Nine type-SR50A Acoustic Emission (AE) sensors were placed on the top surface of the slab and the arrangement was shown in Fig.6. Magnetic ring at bottom of the AE sensor is used to strengthen the connection between the sensor and specimen. But it is useless for the connection between the sensor and concrete material. In order to get true and effective data, wave-guiding rod was used in the test and the detail installation is shown in Fig. 7.

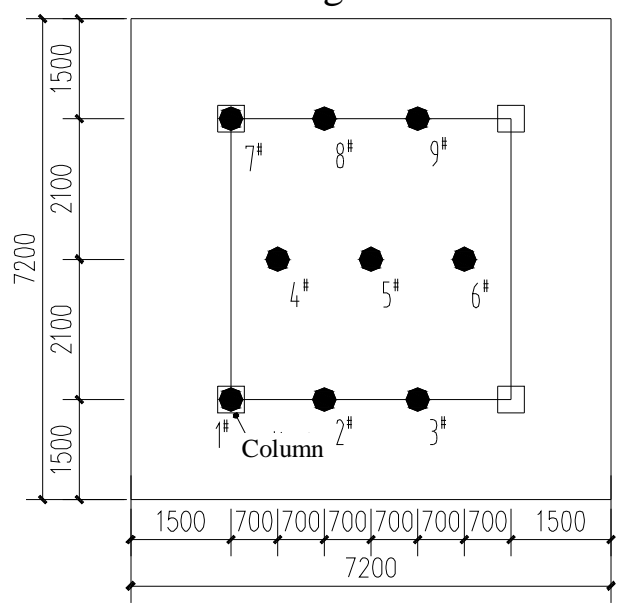

Fig.6 Distribution of AE sensors

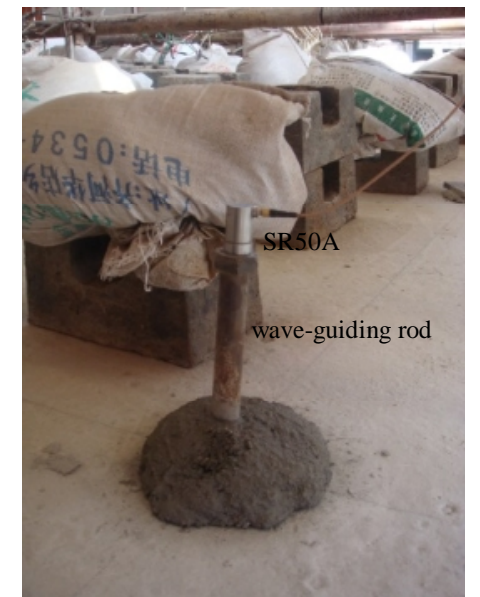

Fig.7 Fixed AE sensor

Fig. 8 shows the top view of the concrete slab after the fire. During the early stages of the fire, oblique cracks of 45 degree with axis between columns rapidly formed beside the four columns. At 5 min, cracks parallel to the axis between columns formed, all the cracks about $0-50 \mathrm{~mm}$ inside of the axis and propagating to the column direction. At $7 \mathrm{~min}$, cracks parallel to the axis between columns formed, these cracks about 350-550 mm outside of the axis and propagating to the column direction and finally crossed with the oblique cracks emerged at beginning. At 9 min, cracks parallel to the axis between columns formed, all these cracks about $350-550 \mathrm{~mm}$ inside of the axis and propagating to the column direction. At $44 \mathrm{~min}$, there were 5 cracks inside of every axis and finally the failure pattern of the flat-plate floor under fire was formed as shown in Fig.8. The failure pattern consistent with those at ambient temperature, so it can be assumed that the yield-line pattern at elevated temperatures should follow the conventional yield-line pattern[11-12].
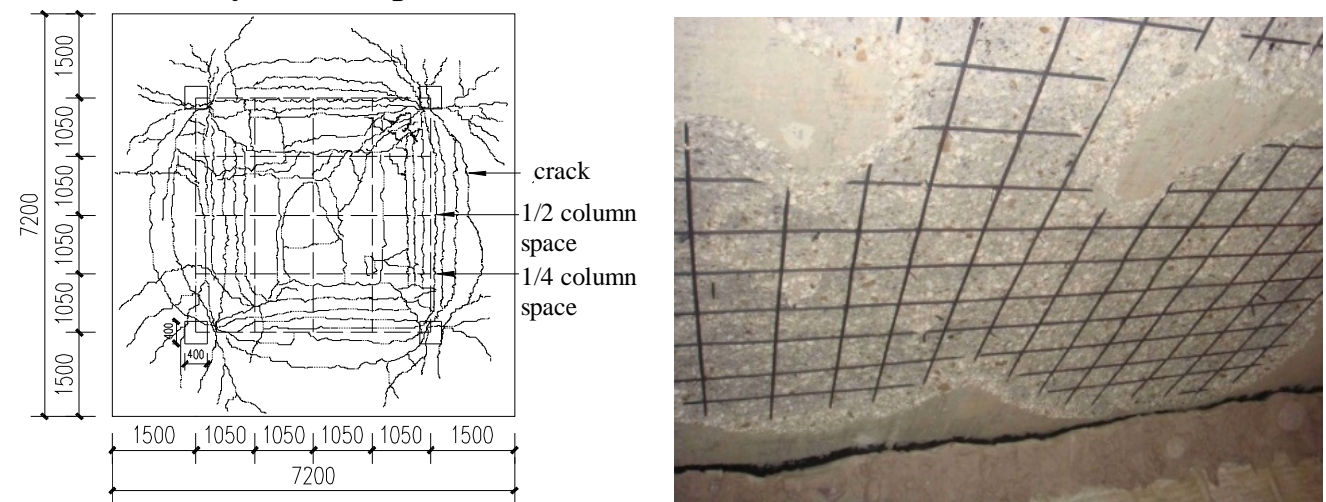

Fig.8 Top crack pattern of the flat-plate floor Fig.9 Bottom failure of the specimen

Fig.9 shows the bottom view of the slab after fire; severe spalling occurred and a large portion of reinforcing bars showed, corresponding to occurrence of big popping noises and noticeable vibration during the test. Examination of the reinforcing bars showed that the bars at the bottom had not ruptured.

The energy rate means energy generated per minute by cracks development. High energy rate means cracks generating and developing fast, so the higher energy rate represents more serious damage occurred to the flat-plate floor under fire. Conversely, the lower energy rate represents less damage occurred to the flat-plate floor under fire. So energy rate can used to estimate the damage of the flat-plate floor under fire. The energy rate and furnace temperature variations were shown in Fig.10. 


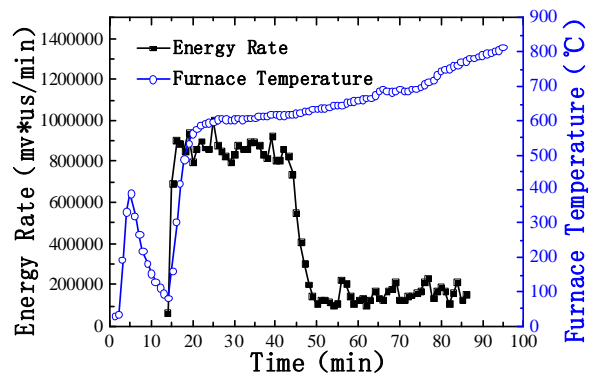

a)Energy rate variation of sensor $1^{\#}$

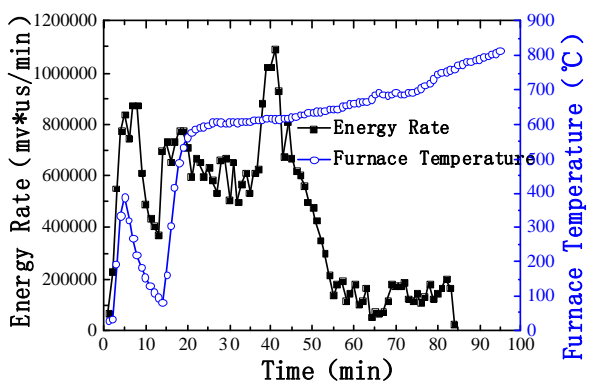

c)Energy rate variation of sensor $3^{\#}$

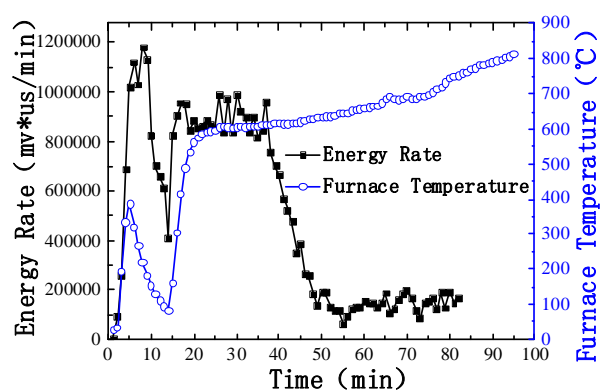

e)Energy rate variation of sensor $5^{\#}$

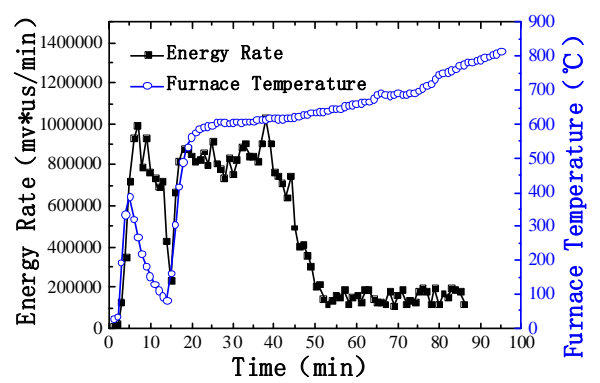

g)Energy rate variation of sensor $7^{\#}$

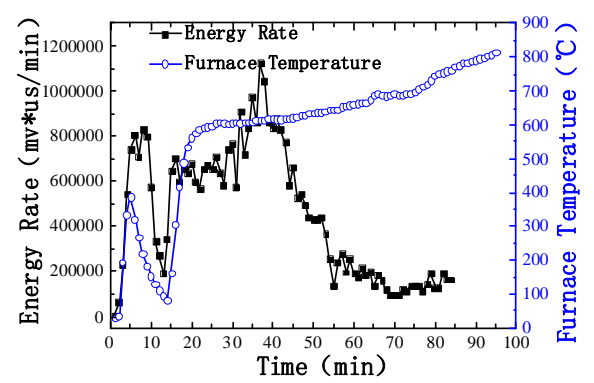

b)Energy rate variation of sensor $2^{\#}$

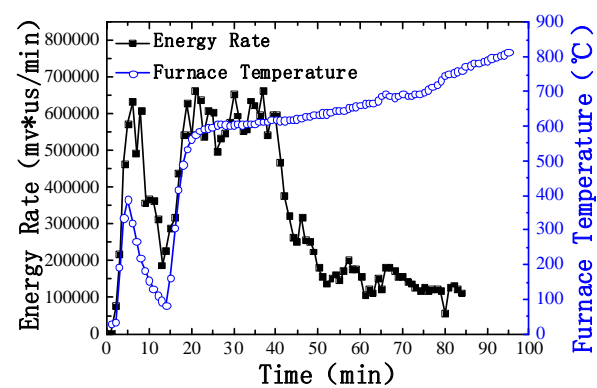

d)Energy rate variation of sensor $4^{\#}$

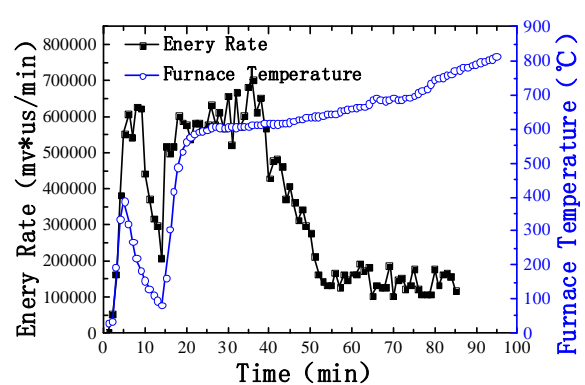

f)Energy rate variation of sensor $6^{\#}$

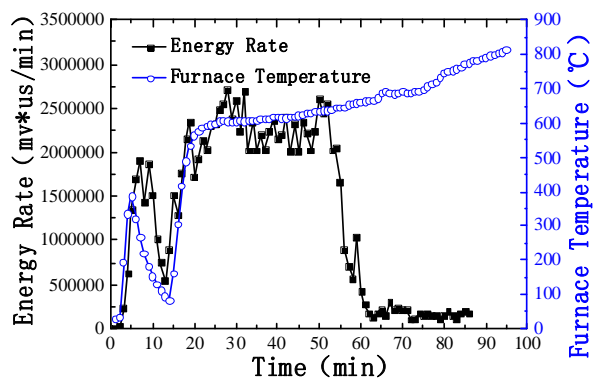

h)Energy rate variation of sensor $8^{\#}$

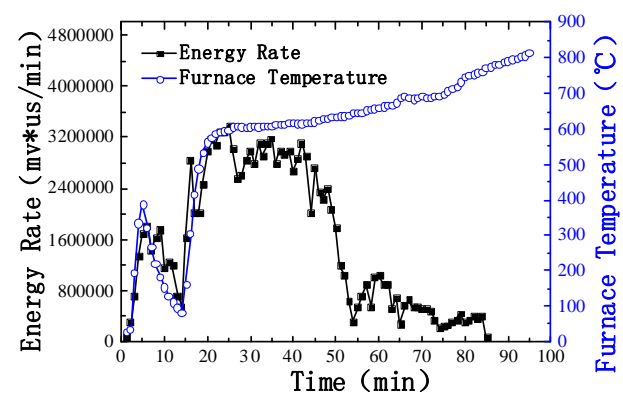

i)Energy rate variation of sensor $9^{\#}$

Fig.10 Variation of the energy rate 
The energy rate increased rapidly at beginning of the test and got the highest value at 4 min, means that the micro-cracks inside of concrete developed fast and the highest energy rate corresponding to the appearance of oblique cracks at $4 \mathrm{~min}$. After $4 \mathrm{~min}$, the energy rate decreased because of the test stopped and it increased again at 6 min when the test restarted. The energy rate kept high values from 14 min to about $40 \mathrm{~min}$, but that didn't mean the endless of cracks occurred. In fact, the phenomenon was caused by cracks development and concrete spalling. In this test, the flat-plate floor was poured in winter and the curing time was about 6 months, and the flat-plate floor kept high moisture content till the test carried out because of the comprehensive effect caused by all of the influence factors. And finally the high moisture content caused serious concrete spalling when tested. The energy rate decreased rapidly from $40 \mathrm{~min}$ to about $55 \mathrm{~min}$, means that there nearly no new crack emerged in this phase, and the energy generated only because the development of existed cracks. From 55 min to the end of the test, the energy rate kept stationary.

\section{Conclusions}

The mechanical behavior and failure pattern of flat-plate floor under fire were discussed in detail. On the basis of experiment, the energy rate of slab under fire was analysed, and the main conclusions can be summarized that:

(1) Based on the full-scale tests, the crack patterns on the top surface of flat-plate floor consistent with those at ambient temperature, so it can be assumed that the yield-line pattern at elevated temperatures should follow the conventional yield-line pattern.

(2) For concrete structure, the concrete spalling has a significant impact on the AE monitoring especially in case of the concrete has a high moisture content.

(3) Monitoring of the flat-plate floor subjected to fire by energy rate can easily find the cracks generating and develping processes and judge the damage degree of the slab, but it can't find the accurate occur time of every crack.

\section{Acknowledgements}

This research was supported by national nature science foundation (50878069) and doctor foundation of university of Jinan(XBS1338), and the author (Chongji Zhu) deeply appreciated their support.

\section{References}

[1] A. Behnia, H.K. Chai, M. Yorikawa, S. Momoki, M. Terazawa, T. Shiotani. Integrated non-destructive assessment of concrete structures under flexure by acoustic emission and travel time tomography, Constr. Build. Mater., 67(Part B,30):202-215(2014).

[2] Shahiron Shahidan, Rhys Pulin, Norazura Muhamad Bunnori, Karen M. Holford. Damage classification in reinforced concrete beam by acoustic emission signal analysis, Constr. Build. Mater. , 45(4):78-86(2013).

[3] A. Benavent, E. Castro, A. Gallego. Evaluation of low-cycle fatigue damage in RC exterior beam-column subassemblages by acoustic emission, Constr. Build. Mater., 24 (10) :1830-1842(2010).

[4] S. Degala, P. Rizzo, K. Ramanathan, K.A. Harries. Acoustic emission monitoring of CFRP reinforced concrete slabs, Constr. Build. Mater., 23 (5):2016-2026(2009).

[5] Mohamed K. ElBatanouny, Paul H. Ziehl, Aaron Laroschea, Jesé Manguala, et al. Acoustic emission monitoring for assessment of prestressed concrete beams, Constr. Build. Mater., 58(15):46-53(2014). 
[6] Francesco Lamonaca, Antonio Carrozzinib, Domenico Grimaldia, Renato S. Olivitob. Improved monitoring of acoustic emissions in concrete structures by multi-triggering and adaptive acquisition time interval, Measurement, 599:227-236(2015).

[7] Thummen, F., Olagnon, C., and Godin, C.. Cyclic fatigue and lifetime of a concrete refractory, $J$. Eur. Ceram. Soc., 26:3357-3363(2006).

[8] Yuyama, S., Li, Z., Yoshizawa, M., Tomokiyo, T., and Uomoto, T.. Evaluation of fatigue damage in reinforced concrete slab by acoustic emission, $N D T \& E$ Int., 34:381-387(2001).

[9] ISO. Fire resistance tests. Elements of building construction. ISO 834, Geneva(1975).

[10] Chongji Zhu, Yuli Dong, Chongzhao Zhu, Experimental study on fire resistance properties of full-scale flate-plate floor subjected to fire, J. Build Struct., 34(3), pp.12-19(2013).

[11] Standard Methods for Testing of Concrete Structures of China. GB50152-92, Beijing (1992). 